\title{
Deoxygenation of graphene oxide using biocompatible reducing agent Ficus carica (dried ripe fig)
}

\author{
Mohd Zaid Ansari ${ }^{1} \cdot$ Weqar Ahmad Siddiqui ${ }^{1}$
}

Received: 10 August 2018 / Accepted: 8 October 2018 / Published online: 15 October 2018

(c) The Author(s) 2018

\section{Abstract}

To address the environmental concerns, a relatively simple, innovative and low-cost procedure has been suggested for synthesis of graphene nanosheets (GNSs). The procedure utilized here for synthesizing GNSs is derived from aqueous suspension of graphene oxide (GO). Ficus carica (FC) is known to be remarkable antioxidant. It is regarded as suitable biocompatible alternative to hazardous and toxic chemicals. This method ensures non-hazardous nature of the deoxygenating agent (FC) as well as their oxidized outcomes. Structural and morphological characterization indicates the absence of oxygen-bearing groups from graphene oxide. Characterization was done by standard techniques such as X-ray crystallography, FTIR, RAMAN, DLS, and UV-Vis spectrophotometry. Morphological investigation of resulting material was also undertaken through standard techniques by FESEM, TEM, HRTEM with SAED pattern. Thermal stability of FC derived graphene was also investigated. The investigation may initiate new routes for preparing GNSs at large scale facilitating a better research and commercial utilization.

\section{Graphical abstract}

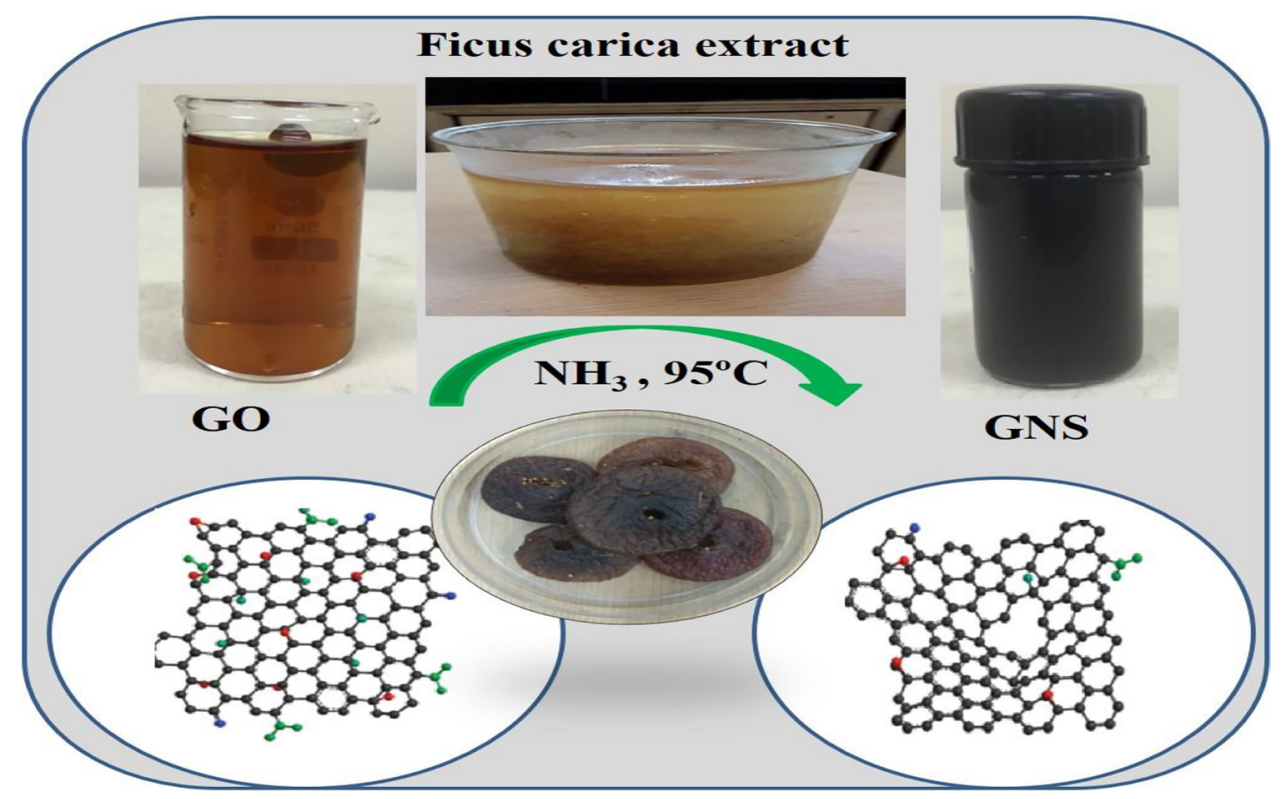

Keywords Green synthesis · Graphene oxide · Graphene nanosheets · Ficus carica extract

Extended author information available on the last page of the article 


\section{Introduction}

Graphene, the wonder material, has become popular among nanomaterial investigators. The path-breaking discovery of graphene was made by Geim and co-workers [1]. Since then there has been active interest in graphene. Remarkable features such as large surface area $\left(2620 \mathrm{~m}^{2} \mathrm{~g}^{-1}\right)$, superior Young's modulus (1.0TPa), exceptional thermal conductivity $\left(\sim 5100 \mathrm{~W} \mathrm{~m}^{-1} \mathrm{~K}^{-1}\right)$, unique chemical strength and large electron movement $\left(2.0 \times 105 \mathrm{~cm}^{2} \mathrm{v}^{-1} \mathrm{~s}^{-1}\right)$ are shown by the graphene sheets [2]. These outstanding features of graphene initiate new ways for multidimensional applications in different segments of technology. They include applications in catalyst engineering [3, 4], lithium-ion batteries [5], chemically derived sensors [6], biosensors [7], anti-bacterial activities [8], delivery of drugs [9], solar cells [10], super capacitors [11], touch panels [12], electromagnetic shielding application [13], water purification [14], and absorption of nonaqueous fluids oils, olefins, aromatic compounds, dyes and organic solvents [15-18]. Due to above-mentioned applications, several methods have been investigated to synthesize graphene. Chemical reduction of graphene oxide (GO) is considered as a superior method for large scale production. The cost is affordable, and time required is of short duration. Identification of green reducing agent for this work is necessary. There onwards, many reductants have been applied for reducing GO. Hydrazine hydrate $\left(\mathrm{N}_{2} \mathrm{H}_{4} \cdot \mathrm{H} 2 \mathrm{O}\right)$, hydrogen bromide $(\mathrm{HBr})$, hydriodic acid with trifluoroacetic acid (HI, TFA), phenol, $p$-toluenesulfonic acid (PTSA) and sodium borohydride $\left(\mathrm{NaBH}_{4}\right)$ have been employed as deoxygenating agents. However, most of these chemicals have limitations as their by-products are hazardous for biosphere. Hence, sophistication is required in using these chemicals. The presence of harmful byproducts may greatly increase production costs on industrial scale [19]. Despite precautions the final product may contain remnants of these harmful chemicals. Its use may not be advisable in several applications such as biomedical field or water purification. To overcome these obstacles, investigators have concentrated more on identifying environmentally suitable reducing agents with higher reducing ability than chemical reducing agent. Consequently, there is an actual need for simple, environment-friendly and cost-effective method for production of graphene. These problems may be solved by green reduction. Researchers have presented various eco-friendly reductants in recent years [20]. They include antioxidants, microorganisms, extracts of plants, vitamins, organic acids and proteins. Such reductants are termed as "green reducing agents" as they are eco-friendly and cost-effective. Further attempts should, however, continue to identify an inexpensive, efficient as well as green deoxygenating agent for production of graphene chemically at large scale.

Ficus carica commonly known as fig is nutritious fruit with useful medicinal properties. Investigation on Ficus carica becomes intensive due to its remarkable nutritional utility and therapeutic properties. Extracts of all parts of Ficus carica possess medicinal properties and may cure several illnesses including cancer [21], diabetes [22], cardiovascular disorders [23], and antimicrobial activity [24]. Ficus carica has these medicinal values due to its precious chemical constituents especially present in ripe fruits. Studies have shown that fig fruit is a rich source of saccharides (mainly glucose, fructose and sucrose), organic acids (citric acid, malic acid), anthocyanin and antioxidant polyphenols [chlorogenic acid (5- $O$-caffeoylquinic acid), catechin, gallic acid, rutin (quercetin-3-O-rutinoside) and syringic acid] [25-29]. These valuable constituents generally have extraordinary binding ability to the oxygen functionalities to yield complementary oxides and various by-products, such as water molecules. These important constituents, especially carbohydrate (glucose and fructose), increase in terms of percentage on ripening of Ficus carica fruits [30-32]. Earlier studies suggested that reducing sugars such as glucose, fructose and sucrose have been used for reducing the GO $[33,34]$. They work via a redox mechanism which relies upon their inherent ability to form closed-chain structures. Both reducing sugar (glucose and fructose) and its oxidized outcomes are eco-friendly. Additionally, their oxidized outcomes act as capping agents for sustaining GNS. Thus, one may conclude that FC carbohydrate content has enough potential to reduce graphene oxide into graphene nanosheets chemically.

\section{Experimental section}

\section{Materials}

Graphite powder, hydrogen peroxide $\left(30 \% \mathrm{H}_{2} \mathrm{O}_{2}\right)$, potassium permanganate $\left(\mathrm{KMnO}_{4}\right)$, sulphuric acid $\left(98 \% \mathrm{H}_{2} \mathrm{SO}_{4}\right)$, and sodium nitrate $\left(\mathrm{NaNO}_{3}\right)$ were procured from Merck, SigmaAldrich, India. The fresh and ripe fruits of Ficus carica were purchased from the local market. All aqueous solutions were prepared with extremely pure water.

\section{Synthesis of graphene oxide}

The modified Hummers' method was used to synthesize graphene oxide [35]. At $0{ }^{\circ} \mathrm{C}, 25.0 \mathrm{~mL}$ of sulfuric acid $(93-96 \%)$ with $(0.5 \mathrm{~g})$ graphite powder was stirred for $20 \mathrm{~min}$. After that, $(0.5 \mathrm{~g})$ of $\mathrm{NaNO}_{3}$ was slowly added to the solution while stirring for $1 \mathrm{~h}$. After that, $\mathrm{KMnO}_{4}(3 \mathrm{~g})$ was added gradually at $0{ }^{\circ} \mathrm{C}$. The whole mixture was heated at $35{ }^{\circ} \mathrm{C}$ for $1 \mathrm{~h}$. Then $40 \mathrm{~mL}$ of water was added into the 
mixture resulting into release of heat which was retained at $95{ }^{\circ} \mathrm{C}$ for $40 \mathrm{~min}$. Again $100 \mathrm{~mL}$ of water was added into the solution. Finally, $30 \% \mathrm{H}_{2} \mathrm{O}_{2}(\sim 10 \mathrm{~mL})$ was added slowly into the solution. The warm mixture was centrifuged and washed with moderately warm water $(150 \mathrm{~mL})$. Subsequently, the sample was washed with plenty of water till neutral $\mathrm{pH}$ was obtained. Afterwards, the sample was treated with basic solution which is heated at $70{ }^{\circ} \mathrm{C}$ for $1 \mathrm{~h}$. A dark brown solution is obtained which centrifuged at (12500 rpm, $30 \mathrm{~min}$ ). The sample was re-dispersed and washed with ethanol. Then $14 \mathrm{mM}$ of $\mathrm{HCl}$ solution was added and stirred again for $1 \mathrm{~h}$ at $70^{\circ} \mathrm{C}$. Again, the solution was centrifuged and washed with ethanol three times. Finally, the sample was dried in an oven at $30^{\circ} \mathrm{C}$ for 3 days to yield GO.

\section{Synthesis of Ficus carica extract}

Figs were cut into small pieces. $100 \mathrm{~g}$ of the dry mass was immersed in $200 \mathrm{~mL}$ of twice-distilled water. Then the mixture was heated at $95^{\circ} \mathrm{C}$ for $60 \mathrm{~min}$ to obtain the extract. The prepared extract was centrifuged at the speed of $10,000 \mathrm{rpm}$. The extract was drained and screened through a cheese cloth to remove impurities. The fresh extract was used immediately for reduction of graphene oxide.

\section{Synthesis of GNSs based on FC extract reduction}

For the synthesis of few layer graphene, $100 \mathrm{ml}$ of FC extract was added slowly through the burette into $100 \mathrm{~mL}$ of uniformly distributed GO solution $(0.2 \mathrm{mg} / \mathrm{mL})$ and the solution was kept stirring for $2 \mathrm{~h}$. After that $2 \mathrm{~mL}$ of ammonia solution is added dropwise in solution and the same is stirred for $12 \mathrm{~h}$ at $95^{\circ} \mathrm{C}$. Then, the incoming stable black solution was centrifuged $(10,000 \mathrm{rpm})$ for $30 \mathrm{~min}$. Finally, the obtained sample was washed thrice with diethyl ether and water solution. Then the resulting GNSs was re-dispersed in ethanolic solution for upcoming characterization.

\section{Characterization}

X-ray diffraction (XRD) studies were performed at room temperature on a D/Max 2500 V/PC (Rigaku Corporation, Tokyo, Japan) at a scan rate of $1 /$ min. Fourier transform infrared spectroscopy (FTIR) investigation was done over the wave number range of $4000-600 \mathrm{~cm}^{-1}$ using a Bruker (Tensor 37) spectrometer (Thermoacoustic, USA). Raman spectra of pure GO, and GNS were obtained using Nano finder 30 (Tokyo Instruments Co., Osaka, Japan) in back scattering geometry with a CCD detector, a 514-nm Ar laser and a $100 \times$ objective mounted on an Olympus optical microscope. Ultraviolet-visible (UV-Vis) spectra were obtained using a U3900 Biochrom Cambridge, UK. The particle size of dispersions was measured by Spectroscatter 201 (Malvern Instruments, Limited, UK). The GO dispersion in water and GNS in DMSO were employed as UV-Vis samples, and their respective solvents were taken as the reference. The morphology of the prepared sample was characterized by TEM (Phillips CM-100 with a tungsten filament), scanning electron microscopy (SEM) was carried out on a S4800 scanning electron microscopy (HITACHI, Japan). Thermogravimetric analysis (TGA) of the samples was performed on (Perkin Elmer Pyris1 TGA Thermogravimetric Analyzer) at a heating rate of $10{ }^{\circ} \mathrm{C} \mathrm{min}-1$ under nitrogen atmosphere.

\section{Results and discussion}

\section{XRD analysis}

In the present work, characterization of powdered sample of graphene oxide and graphene sheets was done by X-ray diffraction technique. The behavior of the synthesized GO was studied in comparison with that of graphene sheets as shown in Fig. 1. The diffraction pattern of GO was studied at $2 \theta=11.13^{\circ}$ (Fig. 1) showing $d$-spacing $\sim 0.78 \mathrm{~nm}$ with respect to graphite [36]. The rise in the spacing is due to the insertion of molecules of water and sandwiching of oxygenbearing functional groups in the sheets of the graphite [37, 38]. After deoxygenation by $\mathrm{FC}$ the $11.13^{\circ}$ peak vanished, and a bump arises, starting from $22^{\circ}$ to $26^{\circ}$. The gap between the layers diminished to $0.39 \mathrm{~nm}$. This may be attributed due to the elimination of water- and oxygen-containing groups from the d-spacing significantly. The bump is also indicative of the elimination of long-range order in graphene [38]. The vanishing of well known (002) reflection arrangement of GO and appearance of a bump at $2 \theta=24^{\circ}$ in the GNS confirms the extensive GO reduction and creation of graphene nanosheets.

\section{Raman spectroscopy}

Raman spectroscopy is a prominent diagnostic tool for determining electronic configuration of chemical compounds. It is extensively applied to describe nanomaterial structure and study disorder and lattice imperfections in carbon nanomaterials. Figure 2a, b demonstrates the Raman analysis of GO powder (blue) and GNS powder (red). The G band and 2D band characteristically indicate the presence of $\mathrm{sp}^{2}$ hybridized $\mathrm{C}-\mathrm{C}$ bonds in graphene [39]. The $\mathrm{G}$ peak is $1595 \mathrm{~cm}^{-1}$ and $1670 \mathrm{~cm}^{-1}$ in the Raman spectrum of GO and GNSs, respectively. It confirms the first-order scattering of the $\mathrm{E}_{2} \mathrm{~g}$ mode. The $\mathrm{D}$ peak at $\sim 1330 \mathrm{~cm}^{-1}$ in both powder samples in the Raman analysis assures the lattice alterations [40]. The decrease in $I_{\mathrm{D}} / I_{\mathrm{G}}$ intensity ratio of GNSs prepared by chemical deoxygenation is frequently informed in earlier 
Fig. 1 XRD patterns of pure GO and GNSs

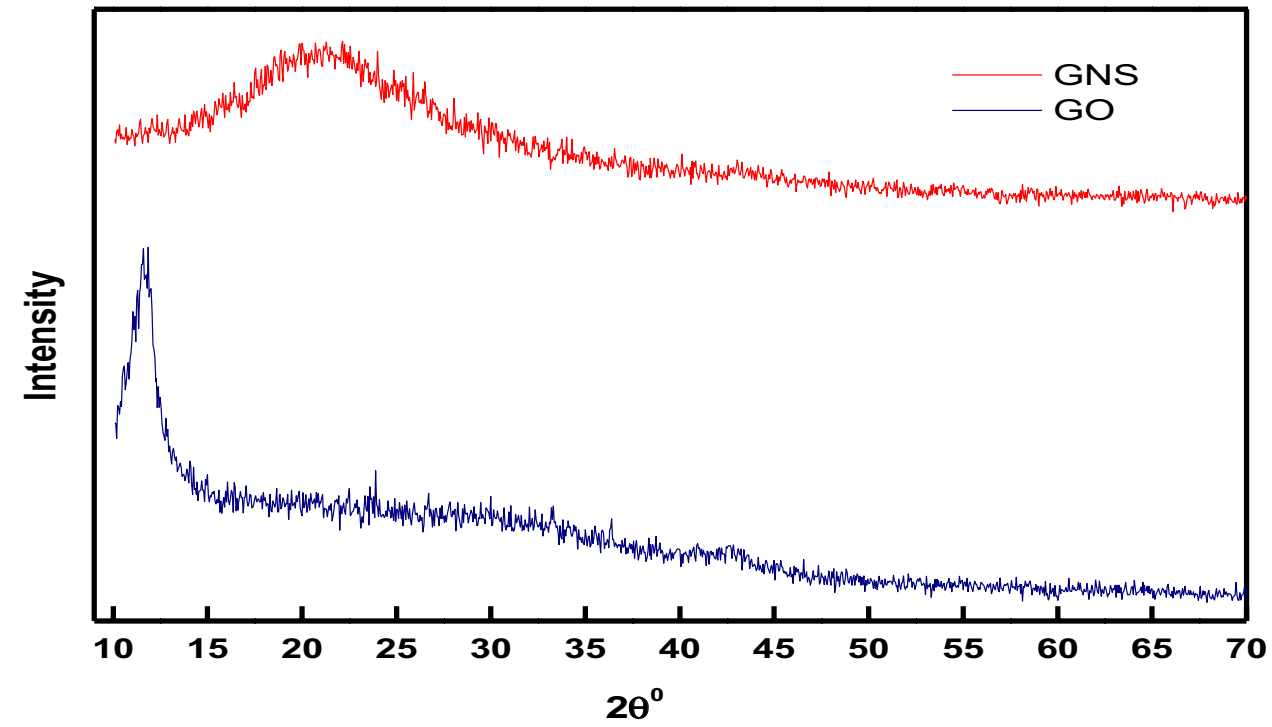

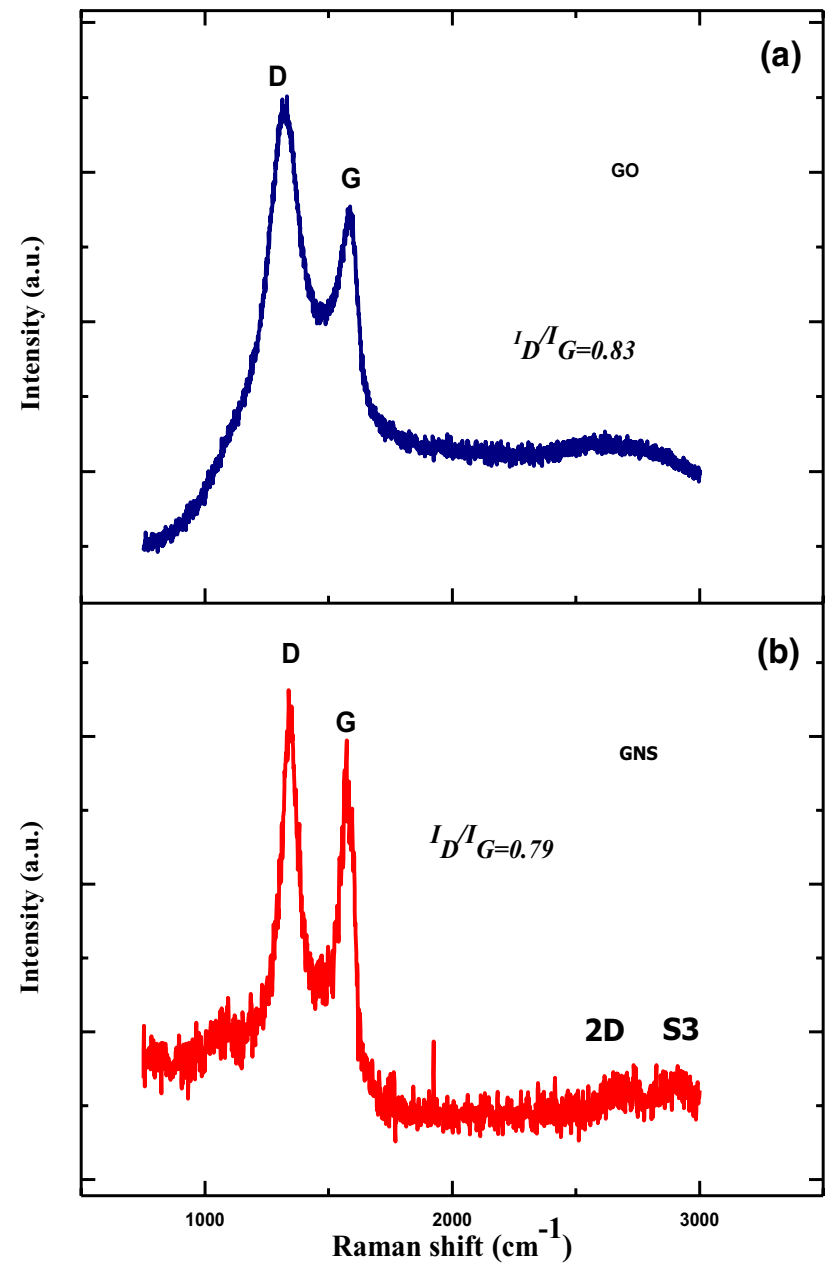

Fig. 2 Raman spectra of GO and GNSs reviews [41]. In the current work, the analysis of $I_{\mathrm{D}} / I_{\mathrm{G}}$ ratio of GNSs exhibited decrement with respect to GO. This indicates rebuilding of $\mathrm{sp}^{2}$ carbon bonds and reduction in the mean size of $\mathrm{sp}^{2}$ region in GO. In addition to this, other bands specifically 2D at $2680 \mathrm{~cm}^{-1}$ and S3 at $\sim 2910 \mathrm{~cm}^{-1}$ were analyzed in GNSs spectra. S3 band is a second-order peak derived from the $D-G$ peak combination [42]. These analyses establish greater extent of graphitization and the absence of charge transfer due to the absence of impurities [41, 42].

\section{UV-Vis spectra of GO and GNSs}

The chemical conversion of GO to GNSs was also investigated by UV-Vis spectrophotometry. As depicted in Fig. 3, the intensity value of two UV-Vis absorption bands centered at 238 and $300 \mathrm{~nm}$ attributing GO, fall progressively with the enhancement in reduction period. UV-Vis spectra illustrate that uncontaminated GO depicts two absorption bands: one at $\sim 238 \mathrm{~nm}$, possibly due to $\pi \rightarrow \pi^{*}$ shift of the $(\mathrm{C}=\mathrm{C})$ bonds. The other peak is at $\sim 300 \mathrm{~nm}$ linked to the $n \rightarrow \pi^{*}$ shift corresponding to the $(\mathrm{C}=\mathrm{O})$ bonds [43, 44]. After reduction by FC, the plasmon band progressively red-shifts to $268 \mathrm{~nm}$. In absorption spectra, this red shift indicates that restoration of electronic conjugation after reduction process [45], while other band completely vanished.

\section{FTIR spectrum of GO and GNSs}

The decrease in the abundance of the oxygen functionalities in GO derived from FC extract was established by FTIR technique (Fig. 4). Presence of a wide band in the range of $3300 \mathrm{~cm}^{-1}$ was referred as hydroxyl group (possibly due to the presence of carboxylic group and 
Fig. 3 UV-Vis absorption spectra obtained for exfoliated GO and GNSs solutions
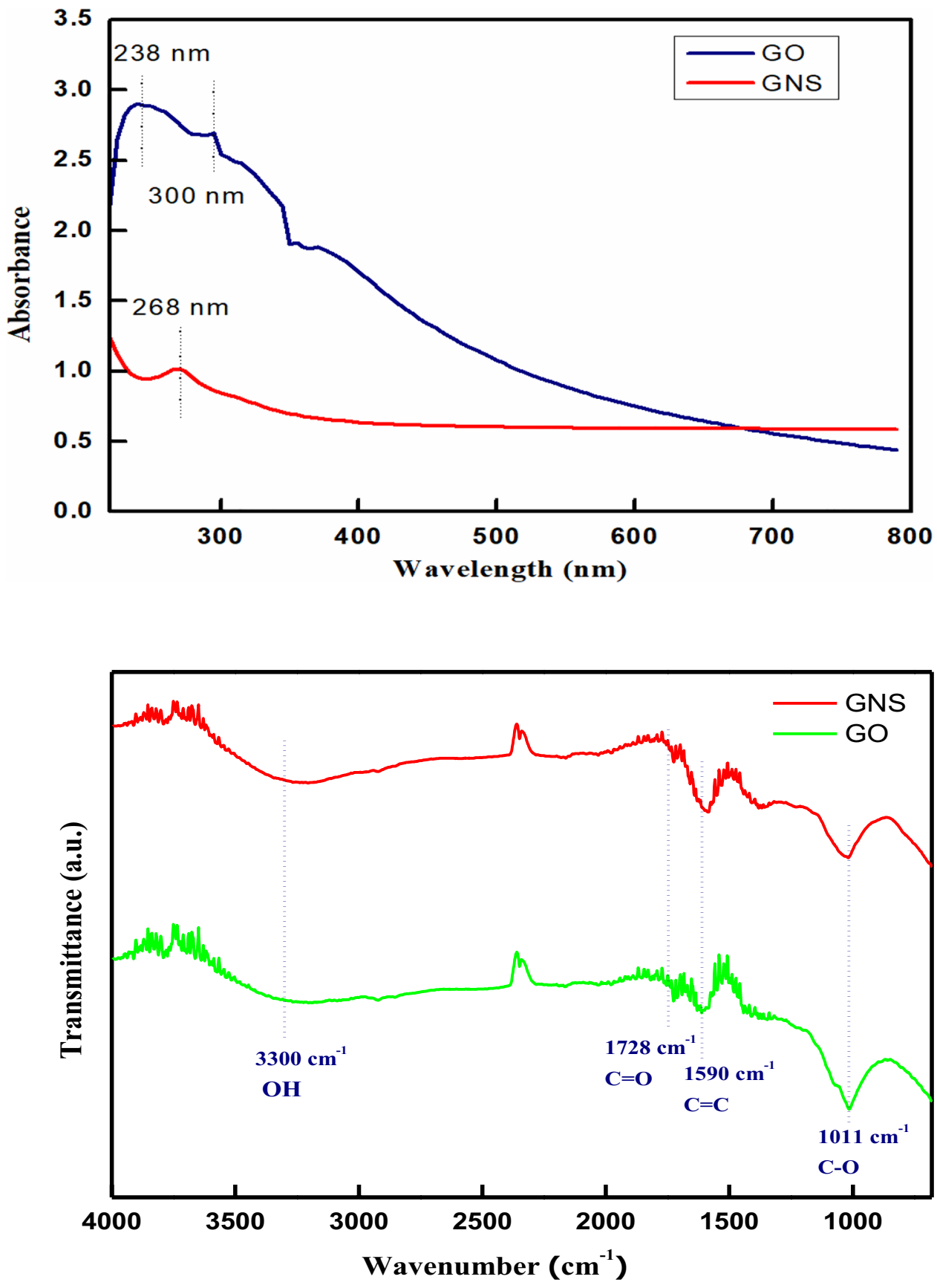

Fig. 4 FTIR spectra obtained for GO and GNSs water molecules) [46]. The peaks at 1728, 1590, and $\sim 1011 \mathrm{~cm}^{-1}$ are believed to be due to presence of ketone $(\mathrm{C}=\mathrm{O})$, epoxide $(\mathrm{C}-\mathrm{O}-\mathrm{C})$ and carboxyl $(\mathrm{COOH}$ and/or $\mathrm{H}_{2} \mathrm{O}$ ) groups, respectively [47, 48], but in the context of GNSs, a remarkable reduction is observed in the intensities of ketonic group along with increase of carbon-carbon double bond. This omission of characteristic oxygen spectral features signifies the remarkable extent to which carbonyl and hydroxyl functionalities are eliminated on reduction of GO and restoration of honey comb structure [49, 50].

\section{Size distribution analysis by DLS}

DLS technique was utilized to determine the mean size of GNSs and GO in aqueous suspension. As revealed in Fig. 5a, an average hydrodynamic thickness of GO layers in water is around $258.5 \mathrm{~nm}$. The particle size of GO is altered to indicate an enhancement in size dimension with a hydrodynamic thickness centered around $291.2 \mathrm{~nm}$ after reduction with FC (Fig. 5b). Liu et al. [51] have measured the diameter in the context of several graphene-related nanomaterials and concluded that GNSs are larger in size compared to GO. 

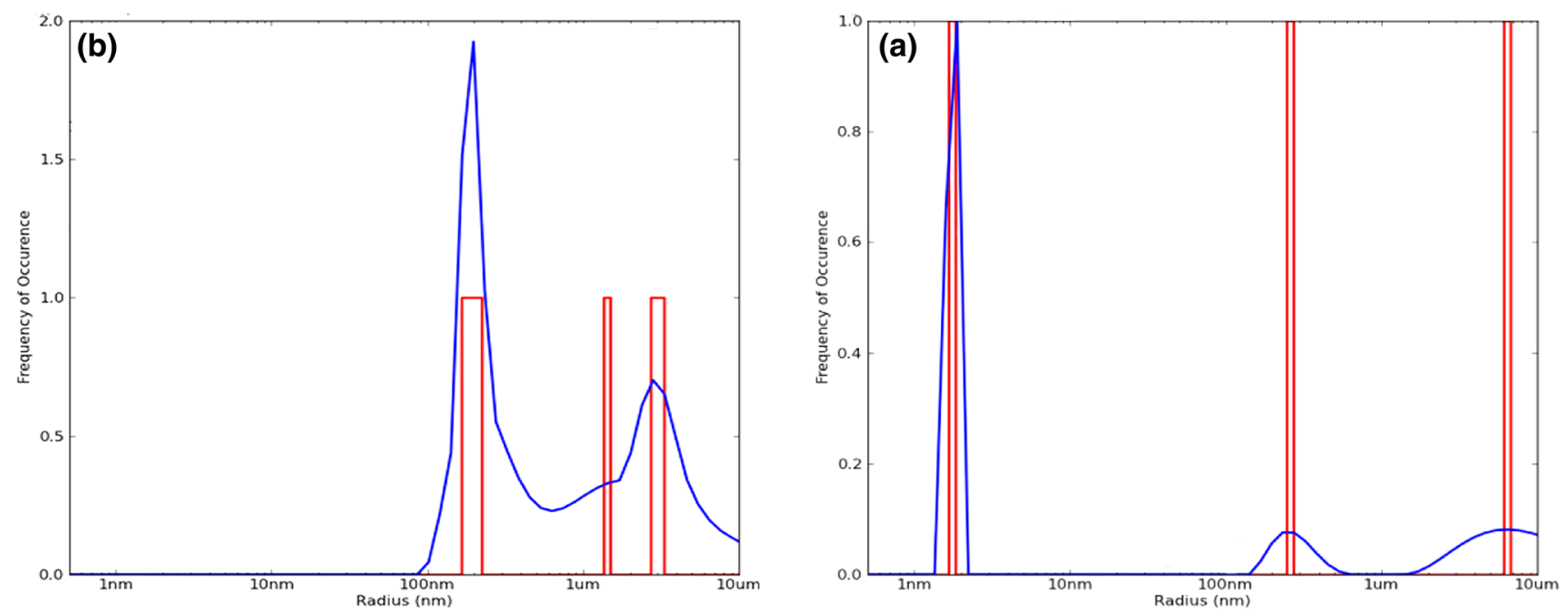

Fig. 5 Particle size distributions of GO (a) and GNSs (b) measured by DLS

Wang et al. also [50] found that after deoxygenation of GO through heparin, the mean thickness of GNSs was larger than that of GO. The GNSs dimensions is approximately ninefold greater than that of GO nanosheets after reduction due to agglomeration of graphene nanosheets [51]. Bacillus marisflavi and Pseudomonas aeruginosa are found to reduce

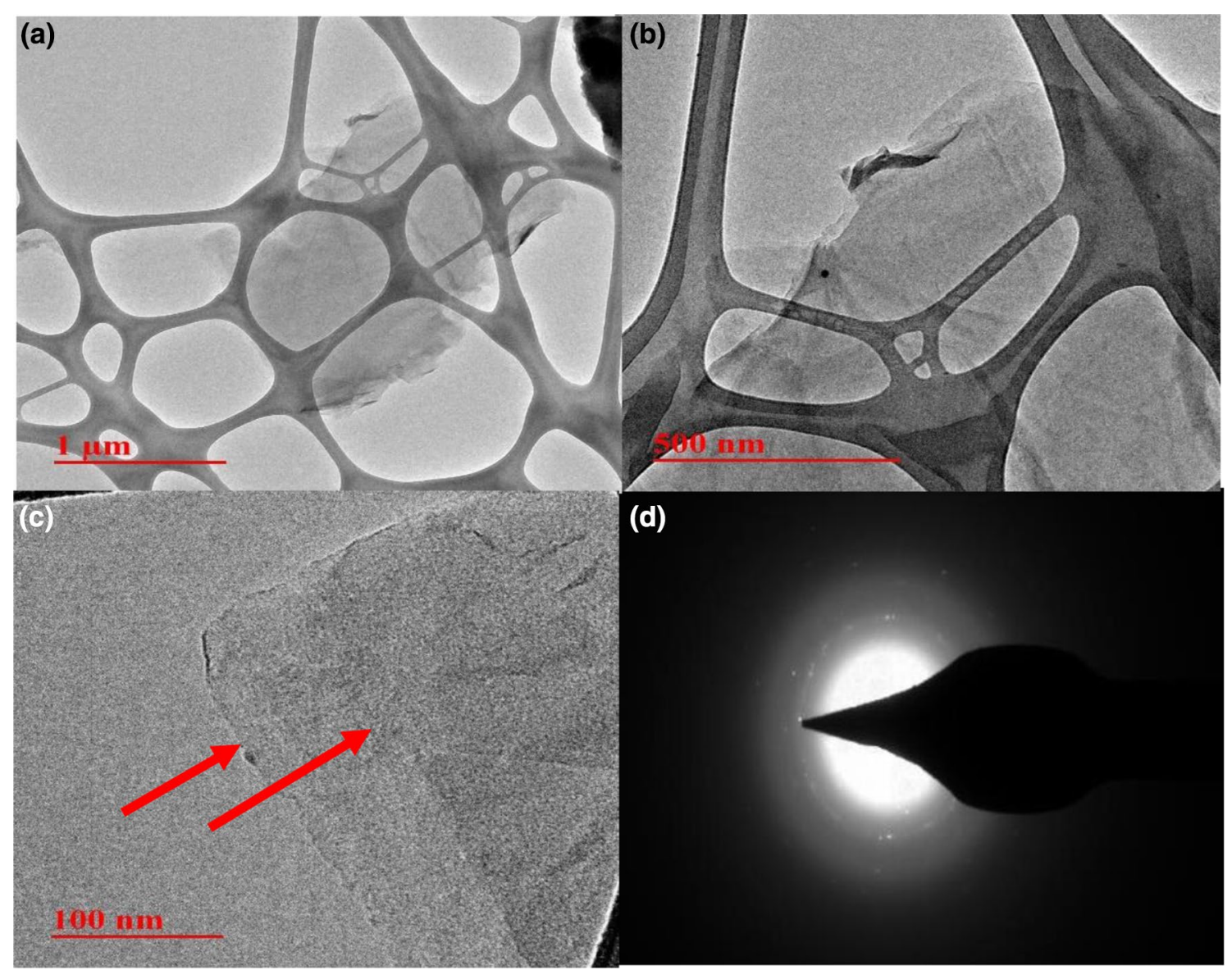

Fig. 6 a, b TEM image of GNS, c HRTEM image and d SAED pattern of graphene nanosheets 
Fig. 7 a, b and $\mathbf{c}$ shows SEM micrograph of GO and GNSs, respectively

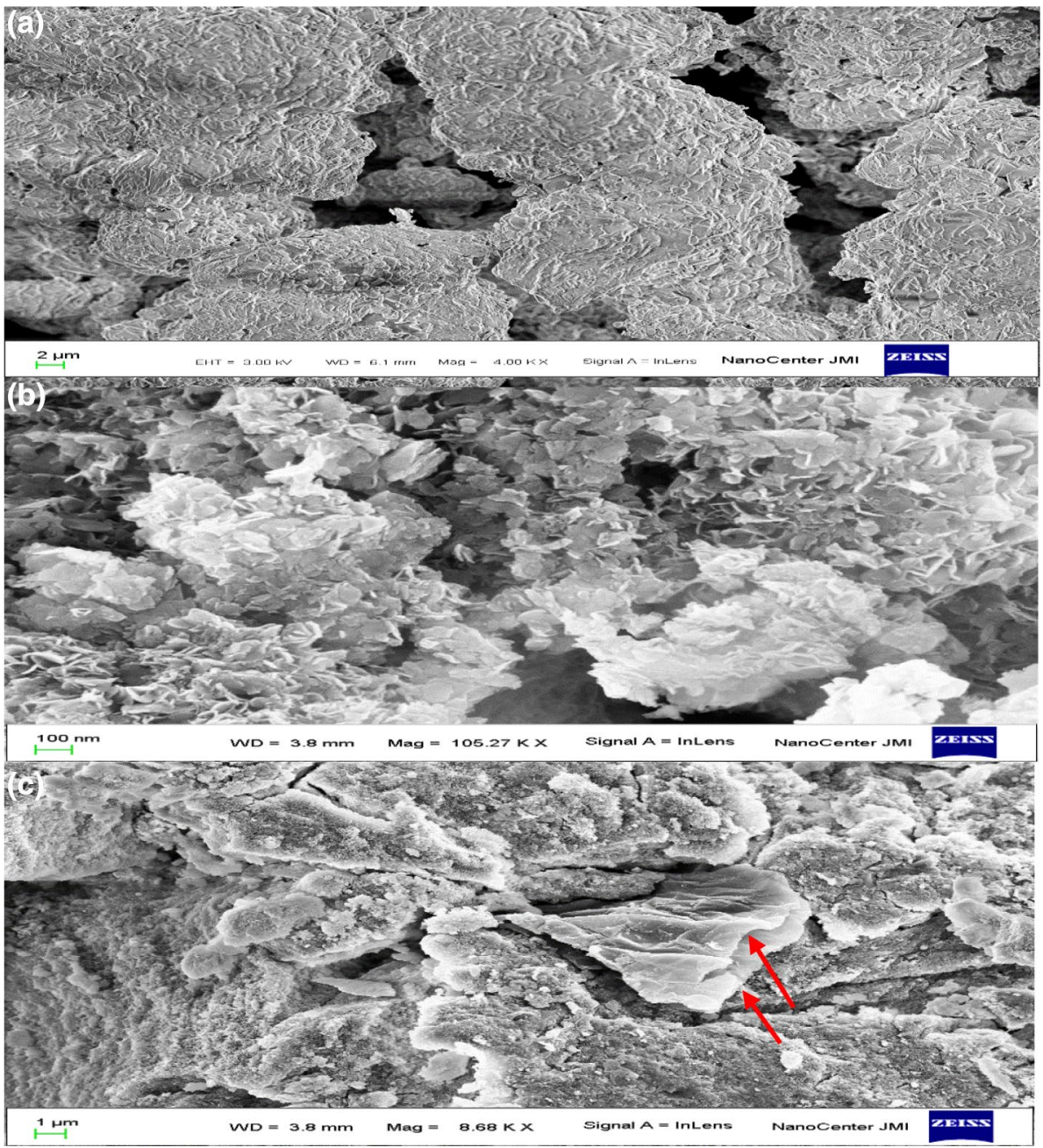

graphene oxide to $2598 \mathrm{~nm}$ and $3799 \mu \mathrm{m}$ size, respectively $[52,53]$. It is demonstrated that FC extract plays a vital role in enhancement of the dimensions of the synthesized graphene nanosheet.

\section{Morphological characterization: TEM and SEM analyses}

The TEM images of GNSs at higher and lower amplifications are seen in Fig. 6a, b, respectively. The presence of translucent and sleek layers of GNSs in TEM picture confirms its persistence under high energy electron beam. The borders of the graphene sheets manage to overlap, permitting cross-sectional view of the films. The bending of layers at borders of layers appears as dark outline. The high-resolution TEM (HRTEM) picture is utilized to approach the number of sheets at several positions. HRTEM picture of GNSs is revealed in Fig. 6c. The development of few layer graphene is apparent in the HRTEM pictures. The small angle electron diffraction (SAED) arrangement of the GNSs also confirms the reduction of graphene sheets [54] as shown in Fig. 6d. The FESEM image shows non-agglomerated graphene oxide in Fig. 7a, while graphene nanosheets appear

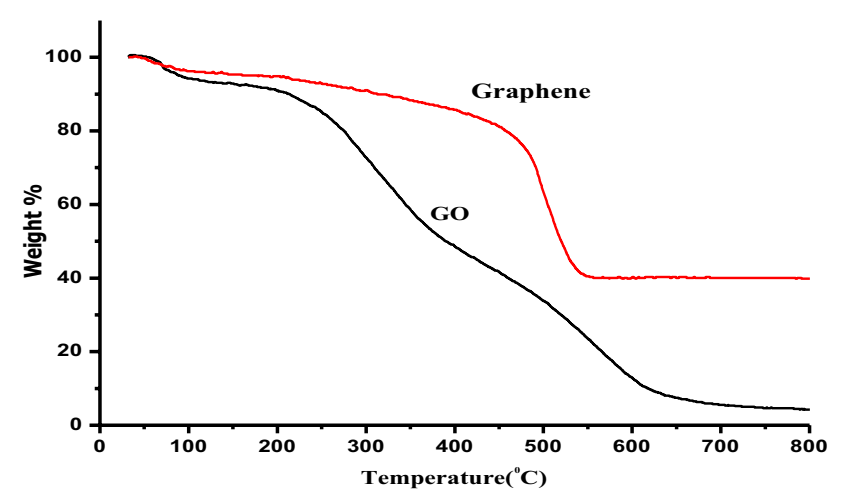

Fig. 8 Thermal analysis of GO and GNSs 
Fig. 9 Proposed mechanism for chemical reduction of $\mathrm{GO}$

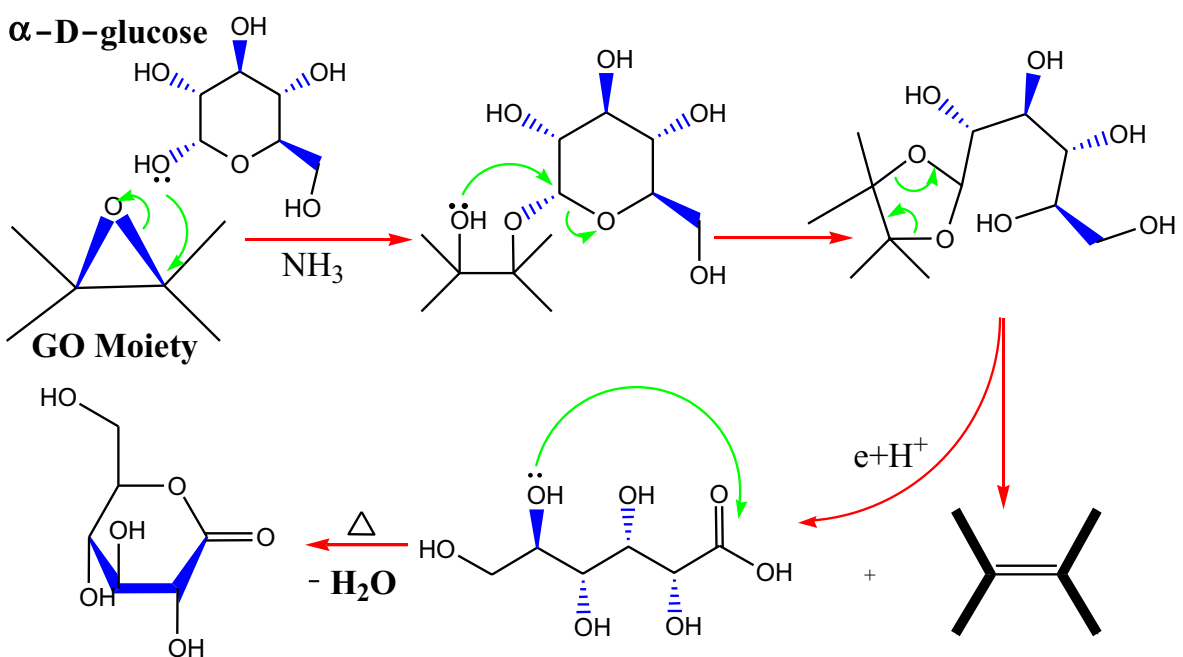

D-(+)-Gluconic acid $\delta$-lactone Gluconic acid
GRAPHENE Moiety significantly wrinkled and look-like flower petals (Fig. 7b, c).

\section{Thermal gravimetric analysis (TGA) study}

We have also inspected the thermal strength of the synthesized GNSs and co-related it with GO using TGA. As revealed in Fig. 8, the $\mathrm{GO}$ exhibits about $7 \%$ weight loss at $105{ }^{\circ} \mathrm{C}$ and then $14-80 \%$ weight loss at $200-600{ }^{\circ} \mathrm{C}$. This loss is due to the exclusion of the bound oxygen functionalities such as $\mathrm{CO}, \mathrm{CO}_{2}$, and steam [45]. In comparison to this, the loss of the oxygen functionalities by reduction enhanced the thermal strength of graphene. It revealed a 3\% weight loss in the nitrogen environment at $105{ }^{\circ} \mathrm{C}$ for GNSs (shown Fig. 8), which is as lower as compared to GO, expressing a cut down in oxygen-containing functionalities. Further critical downfall of GNSs mass at approx. $445-550{ }^{\circ} \mathrm{C}$ is due to the massive break down of carbon framework [34, 45].

\section{Chemistry: mechanism of graphene oxide reduction}

Majority of the content of ripe fruit of $\mathrm{FC}$ is reducing sugar mainly as glucose and fructose responsible for the maximum reduction of GO. Figure 9 shows reduction mechanism of graphene oxide [25, 33]. The use of ammonia in the synthesis is particularly important for the maximum extent of reduction as it leads to a symbiotic increase of the reaction rate of deoxygenation of GO [33]. The graphene sheets possess exceptional spreading steadiness in water. Up to our knowledge there are no previous studies reported on reduction mechanism of graphene oxide by glucose. In basic solution, glucose content of FC extract is first oxidized to gluconic acid which subsequently gets transformed into lactone as a side product and simultaneously reduces GO to GNSs [20, 34]. These oxidized products include plenty of oxygenating groups which form hydrogen bond with the remaining oxygencontaining groups of GNS and provide good dispersion stability.

\section{Conclusion}

The present investigations suggest environment-friendly procedure for deoxygenation of GO by applying FC extract as the dynamic deoxygenating agent. The gained GNS is few layered in structure. Moreover, FC extract has several benefits over traditional reductants such as sodium borohydride and hydrazine hydrate. They are abundantly available, easily extracted from GNS, cost-effective, and suitable for eco-friendly manufacture method. Therefore, it is believed that Ficus carica extract is a powerful eliminator of the harmful chemical reducing agents. It can be utilized to develop graphene on large scale, especially for bio-materials containing graphene sheets.

Open Access This article is distributed under the terms of the Creative Commons Attribution 4.0 International License (http://creativeco mmons.org/licenses/by/4.0/), which permits unrestricted use, distribution, and reproduction in any medium, provided you give appropriate credit to the original author(s) and the source, provide a link to the Creative Commons license, and indicate if changes were made. 


\section{References}

1. Novoselov, K.S., Geim, A.K., Morozov, S.V., Jiang, D.A., Zhang, Y., Dubonos, S.V., Firsov, A.A.: Electric field effect in atomically thin carbon films. Science 306, 666-669 (2004)

2. Chabot, V., Higgins, D., Yu, A., Xiao, X., Chen, Z., Zhang, J.: A review of graphene and graphene oxide sponge: material synthesis and applications to energy and the environment. Energy Environ. Sci. 7, 1564-1596 (2014)

3. Metin, Ö., Ho, S.F., Alp, C., Can, H., Mankin, M.N., Gültekin, M.S., Sun, S.: Ni/Pd core/shell nanoparticles supported on graphene as a highly active and reusable catalyst for Suzuki-Miyaura cross-coupling reaction. Nano Res. 6, 10-18 (2013)

4. Lu, Y.H., Zhou, M., Zhang, C., Feng, Y.P.: Metal-embedded graphene: a possible catalyst with high activity. J. Phys. Chem. C 113, 20156-20160 (2009)

5. Wu, Z.S., Ren, W., Wen, L., Gao, L., Zhao, J., Chen, Z., Cheng, H.M.: Graphene anchored with $\mathrm{Co}_{3} \mathrm{O}_{4}$ nanoparticles as anode of lithium ion batteries with enhanced reversible capacity and cyclic performance. ACS Nano 4, 3187-3194 (2010)

6. Fowler, J.D., Allen, M.J., Tung, V.C., Yang, Y., Kaner, R.B., Weiller, B.H.: Practical chemical sensors from chemically derived graphene. ACS Nano 3, 301-306 (2009)

7. Liu, Y., Yu, D., Zeng, C., Miao, Z., Dai, L.: Biocompatible graphene oxide-based glucose biosensors. Langmuir 26, 6158$6160(2010)$

8. Hu, W., Peng, C., Luo, W., Lv, M., Li, X., Li, D., Fan, C.: Graphene-based antibacterial paper. ACS Nano 4, 4317-4323 (2010)

9. Sun, X., Liu, Z., Welsher, K., Robinson, J.T., Goodwin, A., Zaric, S., Dai, H.: Nano-graphene oxide for cellular imaging and drug delivery. Nano Res. 1, 203-212 (2008)

10. Guo, C.X., Wang, M., Chen, T., Lou, X.W., Li, C.M.: A hierarchically nanostructured composite of $\mathrm{MnO} 2 /$ conjugated polymer/graphene for high-performance lithium ion batteries. Adv. Energy Mater. 1, 736-741 (2011)

11. Guo, C.X., Li, C.M.: A self-assembled hierarchical nanostructure comprising carbon spheres and graphene nanosheets for enhanced supercapacitor performance. Energy Environ. Sci. 4, 4504-4507 (2011)

12. Jo, G., Choe, M., Lee, S., Park, W., Kahng, Y.H., Lee, T.: The application of graphene as electrodes in electrical and optical devices. Nanotechnol. 23, 112001 (2012)

13. Eswaraiah, V., Sankaranarayanan, V., Ramaprabhu, S.: Graphene-based engine oil nanofluids for tribological applications. ACS Appl. Mater. Interfaces. 3, 4221-4227 (2011)

14. Sui, Z., Meng, Q., Zhang, X., Ma, R., Cao, B.: Green synthesis of carbon nanotube-graphene hybrid aerogels and their use as versatile agents for water purification. J. Mater. Chem. 22, 8767-8771 (2012)

15. Zhao, Y., Jiang, C., Hu, C., Dong, Z., Xue, J., Meng, Y., Qu, L.: Large-scale spinning assembly of neat, morphology-defined, graphene-based hollow fibres. ACS Nano 7, 2406-2412 (2013)

16. Sun, H., Xu, Z., Gao, C.: Multifunctional, ultra-flyweight, synergistically assembled carbon aerogels. Adv. Mater. 25, 2554-2560 (2013)

17. Bi, H., Xie, X., Yin, K., Zhou, Y., Wan, S., He, L., Ruoff, R.S.: Spongy graphene as a highly efficient and recyclable sorbent for oils and organic solvents. Adv. Funct. Mater. 22, 4421-4425 (2012)

18. Dong, X., Chen, J., Ma, Y., Wang, J., Chan-Park, M.B., Liu, X., Chen, P.: Superhydrophobic and super oleophilic hybrid foam of graphene and carbon nanotube for selective removal of oils or organic solvents from the surface of water. Chem. Commun. 48, 10660-10662 (2012)
19. Zhao, J., Ren, W., Cheng, H.M.: Graphene sponge for efficient and repeatable adsorption and desorption of water contaminations. J. Mater. Chem. 22, 20197-20202 (2012)

20. Thakur, S., Karak, N.: Alternative methods and nature-based reagents for the reduction of graphene oxide: a review. Carbon $\mathbf{9 4}$, 224-242 (2015)

21. Wang, J., Wang, X., Jiang, S., Lin, P., Zhang, J., Lu, Y., Yang, H.: Cytotoxicity of fig fruit latex against human cancer cells food and chemical toxicology. Food Chem. Toxicol. 46, 1025-1033 (2008)

22. Wojdyło, A., Nowicka, P., Carbonell-Barrachina, Á.A., Hernández, F.: Phenolic compounds, antioxidant and antidiabetic activity of different cultivars of Ficus carica L. J. Funct. Foods. 25, 421-432 (2016)

23. Mawa, S., Husain, K., Jantan, I.: Ficus carica L. (Moraceae) phytochemistry, traditional uses and biological activities. Evid. Based Complement. Altern. Med. 2013, 1-8 (2013)

24. Aref, H.L., Salah, K.B., Chaumont, J.P., Fekih, A., Aouni, M., Said, K.: In vitro antimicrobial activity of four Ficus carica latex fractions against resistant human pathogens (antimicrobial activity of Ficus carica latex). Pak. J. Pharmcol. 23, 53-58 (2010)

25. Aljane, F., Ferchichi, A.: Postharvest chemical properties and mineral contents of some fig (Ficus carica L.) cultivars in Tunisia. J. Food Agric. Environ. 7, 212 (2009)

26. Veberic, R., Colaric, M., Stampar, F.: Phenolic acids and flavonoids of fig fruit (Ficus carica L.) in the northern Mediterranean region. Food Chem. 106, 153-157 (2008)

27. Vallejo, F., Marín, J.G., Tomás-Barberán, F.A.: Phenolic compound content of fresh and dried figs (Ficus carica L.). Food Chem. 130, 485-492 (2012)

28. Solomon, A., Golubowicz, S., Yablowicz, Z., Grossman, S., Bergman, M., Gottlieb, H.E., Flaishman, M.A.: Antioxidant activities and anthocyanin content of fresh fruits of common fig (Ficus carica L.). J Agric. Food Chem. 54, 7717-7723 (2006)

29. Çalişkan, O., Polat, A.A.: Phytochemical and antioxidant properties of selected fig (Ficus carica L.) accessions from the eastern Mediterranean region of Turkey. Sci. Hortic. 128, 473-478 (2011)

30. Slatnar, A., Klancar, U., Stampar, F., Veberic, R.: Effect of drying of figs (Ficus carica L.) on the contents of sugars, organic acids, and phenolic compounds. J. Agric. Food Chem. 59, 11696-11702 (2011)

31. Freiman, Z.E., Doron-Faigenboim, A., Dasmohapatra, R., Yablovitz, Z., Flaishman, M.A.: High-throughput sequencing analysis of common fig (Ficus carica L.) transcriptome during fruit ripening. Tree Genet. Genomes 10, 923-935 (2014)

32. Marrelli, M., Menichini, F., Statti, G.A., Bonesi, M., Duez, P., Menichini, F., Conforti, F.: Changes in the phenolic and lipophilic composition, in the enzyme inhibition and antiproliferative activity of Ficus carica L. cultivar Dottato fruits during maturation. Food Chem. Toxicol. 50, 726-733 (2012)

33. Zhu, C., Guo, S., Fang, Y., Dong, S.: Reducing sugar: new functional molecules for the green synthesis of graphene nanosheets. ACS Nano 4, 2429-2437 (2010)

34. Ansari, M.Z., Shoeb, M., Nayab, P.S., Mobin, M., Khan, I., Siddiqui, W.A.: Honey mediated green synthesis of graphene based $\mathrm{NiO} / \mathrm{Cu} 2 \mathrm{O}$ nanocomposite ( $\mathrm{Gr} @ \mathrm{NiO} / \mathrm{Cu} 2 \mathrm{O} \mathrm{NCs})$ : Catalyst for the synthesis of functionalized Schiff-base derivatives. J. Alloys Compd. 738, 56-71 (2018)

35. Li, Y., Wu, Y.: Co assembly of graphene oxide and nanowires for large-area nanowire alignment. J. Am. Chem. Soc. 131, 58515857 (2009)

36. Krishnamoorthy, K., Veerapandian, M., Zhang, L.H., Yun, K., Kim, S.J.: Antibacterial efficiency of graphene nanosheets against pathogenic bacteria via lipid peroxidation. J. Phys. Chem. C 116, 17280-17287 (2012) 
37. Khanra, P., Kuila, T., Kim, N.H., Bae, S.H., Yu, D.S., Lee, J.H.: Simultaneous bio-functionalization and reduction of graphene oxide by baker's yeast. Chem. Eng. J. 183, 526-533 (2012)

38. Malas, A., Das, C.K.: Effect of graphene oxide on the physical, mechanical and thermo-mechanical properties of neoprene and chloro-sulfonated polyethylene vulcanizates. Compos. B 79, 639-648 (2015)

39. Ferrari, A.C., Basko, D.M.: Raman spectroscopy as a versatile tool for studying the properties of graphene. Nat. Nanotechnol. 8, 235 (2013)

40. Cui, P., Lee, J., Hwang, E., Lee, H.: One-pot reduction of graphene oxide at sub-zero temperatures. Chem. Commun. 47, 12370-12372 (2011)

41. El-Khodary, S.A., El-Enany, G.M., El-Okr, M., Ibrahim, M.: Preparation and characterization of microwave reduced graphite oxide for high-performance supercapacitors. Electrochim. Acta 150, 269-278 (2014)

42. Bajpai, R., Roy, S., Rafiee, J., Koratkar, N., Misra, D.S.: Graphene supported nickel nanoparticle as a viable replacement for platinum in dye sensitized solar cells. Nanoscale 4, 926-930 (2012)

43. Upadhyay, R.K., Soin, N., Bhattacharya, G., Saha, S., Barman, A., Roy, S.S.: Grape extract assisted green synthesis of reduced graphene oxide for water treatment application. Mater. Lett. 160, 355-358 (2015)

44. Xu, L.Q., Liao, Y.B., Li, N.N., Li, Y.J., Zhang, J.Y., Wang, Y.B., Li, C.M.: Vancomycin-assisted green synthesis of reduced graphene oxide for antimicrobial applications. J. Colloid Interface Sci. 514, 733-739 (2018)

45. Sadhukhan, S., Ghosh, T.K., Rana, D., Roy, I., Bhattacharyya, A., Sarkar, G., Chattopadhyay, D.: Studies on synthesis of reduced graphene oxide (RGO) via green route and its electrical property. Mater. Res. Bull. 79, 41-51 (2016)

46. Fan, Z., Wang, K., Wei, T., Yan, J., Song, L., Shao, B.: An environmentally friendly and efficient route for the reduction of graphene oxide by aluminium powder. Carbon 48, 1686-1689 (2010)

\section{Affiliations}

\section{Mohd Zaid Ansari ${ }^{1}$. Weqar Ahmad Siddiqui ${ }^{1}$}

Mohd Zaid Ansari

mohd4net@gmail.com
47. Haghighi, B., Tabrizi, M.A.: Green-synthesis of reduced graphene oxide nanosheets using rose water and a survey on their characteristics and applications. RSC Adv. 3, 13365-13371 (2013)

48. Fernández-Merino, M.J., Guardia, L., Paredes, J.I., Villar-Rodil, S., Solís-Fernández, P., Martínez-Alonso, A., Tascon, J.M.: Vitamin $\mathrm{C}$ is an ideal substitute for hydrazine in the reduction of graphene oxide suspensions. J. Phys. Chem. C 114, 6426-6432 (2010)

49. Thakur, S., Karak, N.: One-step approach to prepare magnetic iron oxide/reduced graphene oxide nanohybrid for efficient organic and inorganic pollutants removal. Mater. Chem. Phys. 144, 425-432 (2014)

50. Wang, Y., Zhang, P., Liu, C.F., Zhan, L., Li, Y.F., Huang, C.Z.: Green and easy synthesis of biocompatible graphene for use as an anticoagulant. RSC Adv. 2, 2322-2328 (2012)

51. Liu, S., Zeng, T.H., Hofmann, M., Burcombe, E., Wei, J., Jiang, R., Chen, Y.: Antibacterial activity of graphite, graphite oxide, graphene oxide, and reduced graphene oxide: membrane and oxidative stress. ACS Nano 5, 6971-6980 (2011)

52. Gurunathan, S., Han, J.W., Eppakayala, V., Kim, J.H.: Biocompatibility of microbially reduced graphene oxide in primary mouse embryonic fibroblast cells. J Colloids Surf. B 105, 58-66 (2013)

53. Gurunathan, S., Han, J., Kim, J.H.: Humanin: a novel functional molecule for the green synthesis of graphene. J Colloids Surf. B 111, 376-383 (2013)

54. Chen, L., Lei, J., Wang, F., Wang, G., Feng, H.: Facile synthesis of graphene sheets from fluorinated graphite. RSC Adv. 5, 40148-40153 (2015)

Publisher's Note Springer Nature remains neutral with regard to jurisdictional claims in published maps and institutional affiliations.

1 Department of Applied Science and Humanities, Faculty of Engineering and Technology, Jamia Millia Islamia, New Delhi 110025, India 